\title{
Mania in Wolfram's Disease: From Bedside to Bench
}

\author{
Seshadri Sekhar Chatterjee ${ }^{1}$, Sayantanava Mitra $^{2}$, Salil Kumar Pal ${ }^{3}$ \\ ${ }^{1}$ Department of Psychiatry, Medical College, ${ }^{2}$ Consultant Psychiatrist, ${ }^{3}$ Department of Endocrinology, Calcutta National Medical College, \\ Kolkata, India
}

\begin{abstract}
Wolfram syndrome is a relatively unexplored entity in clinical psychiatry. Historically, the discovery of a specific WFS1 gene had generated huge fanfare regarding specific genetic causations of psychiatric disorders. While the initial enthusiasm has faded now, association of Wolfram syndrome with psychiatric illnesses like schizophrenia, psychosis and suicidal behavior still remain important for understanding biological underpinnings of such disorders. We report a case of Wolfram syndrome presenting with multiple manic episodes, discuss possible genetic underpinnings for the affective symptoms and then discuss certain issues regarding management.
\end{abstract}

KEY WORDS: Wolfram syndrome; Bipolar Disorder; Comorbidity.

\section{INTRODUCTION}

Among all the neurodevelopmental disorders associated with psychiatric abnormalities, Wolfram syndrome (WS) is an important but relatively unexplored entity. ${ }^{1)}$ The discovery of a specific mutation in WFS1 gene had ushered in an era of focus on specific genetic causations of psychiatric disorders. Though the initial enthusiasm has faded since then, the fact that mere heterozygous presence of WFS gene could increase the possibility of many psychiatric illnesses like schizophrenia, psychosis and suicidal behavior by many folds warrants attention to WS. ${ }^{2)}$ There is no specific data regarding mania in Wolfram disease. We here report one case of WS presenting with multiple manic episodes, and try to elucidate psychiatric symptomatology in this patient along with possible genetic underpinnings for the same. We further discuss the issues regarding management.

\section{CASE}

Our patient, currently 22 years old male, first experi-

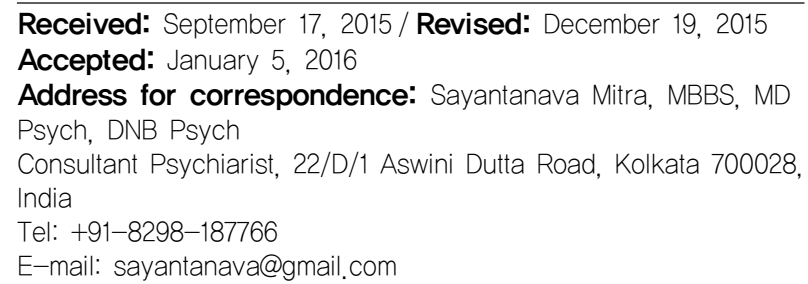

enced rapid weight loss and increasing urinary output at 6-year age and was diagnosed with diabetes mellitus (DM) and subsequently put on insulin. The patient developed dimness in vision with difficulty in colour recognition at the age of 10 years, and thereafter hearing difficulty at 14 years. At 16 years of age, the patient developed an episode of behavioral disturbances characterized by increased physical activity, bossy attitude, along with arrogance, decreased sleep and overtly sexual behavior; all of which subsided with (unnamed) medication. He stopped taking medicines thereafter.

Since then there were multiple hospital admissions for polyuria. At age of 22 years, this patient came to us with reappearance of all the previous mood symptoms in increased severity along with some psychotic symptoms like delusion of grandiosity (that he holds a high post in Indian intelligence and has special connections with President of India). He had an increase in speech productivity, elated mood and increased psychomotor activities. His Young Mania Rating Scale score was 26. He was diagnosed as Bipolar Affective Disorder, current episode manic with psychotic symptoms as per International Classification of Diseases-10 Diagnostic Criteria for Research.

The patient was of average built, with body mass index of $21.72 \mathrm{~kg} / \mathrm{m}^{2}$. Ophthalmological examination showed decreased visual acuity (right 6/30, left 6/60) bilateral optic atrophy, nondiabetic retinopathy, constricted field of vision and problem in color detection. He had bilateral

(c) This is an Open-Access article distributed under the terms of the Creative Commons Attribution Non-Commercial License (http://creativecommons.org/licenses/by-nc/4.0) which permits unrestricted non-commercial use, distribution, and reproduction in any medium, provided the original work is properly cited. 
Table 1. Diagnostic criteria as set by EURO-WABB group developed Wolfram syndrome guideline ${ }^{3)}$ and findings in our case

\begin{tabular}{|c|c|}
\hline Criteria & Our case \\
\hline \multicolumn{2}{|l|}{ Major } \\
\hline o Diabetes mellitus < 16 yr (87\%) & Present \\
\hline O Optic Atrophy $<16$ yr (80\%) & Present \\
\hline \multicolumn{2}{|l|}{ Minor criteria } \\
\hline o Diabetes insipidious $(<42 \%)$ & Present \\
\hline o Diabetis mellitus $>16$ yr (4\%) & Not applicable \\
\hline o Optic atrophy $>16$ yr (7\%) & Not applicable \\
\hline O Sensorinural deafness (48\%) & Present \\
\hline o Neurological signs (ataxia, epilepsy, cognitive impairment) (29\%) & Present \\
\hline o Renal tract abnormalities (structural or functional) $(33 \%)$ & Present \\
\hline ○ 1 loss of function mutation in WFS1/CISD2 and/or family history of Wolfram syndrome & Not done \\
\hline \multicolumn{2}{|l|}{ Others suggestible evidence } \\
\hline o Hypogonadism in males (6\%) & Present \\
\hline - Absence of type 1 diabetes auto-antibodies & Not done \\
\hline \multicolumn{2}{|l|}{ o Bilateral cataracts (1\%) } \\
\hline O Psychiatric disprder (26\%) & Absent \\
\hline \multirow[t]{2}{*}{ - Gastrointestinal disorders (5\%) } & Present \\
\hline & Absent \\
\hline \multicolumn{2}{|l|}{ Minimum required } \\
\hline 2 major & \\
\hline \multicolumn{2}{|l|}{$\begin{array}{l}2 \text { major } \\
\text { OR }\end{array}$} \\
\hline \multicolumn{2}{|l|}{1 major plus 2 minor criteria } \\
\hline \multicolumn{2}{|l|}{ OR } \\
\hline 2 pathological WFS1 or CISD2 mutations are identified & \\
\hline
\end{tabular}

Percentages in parentheses refer to prevalence of feature in EURO-WABB registry.

sensorineural deafness, more on left side. An endocrinological referral confirmed diabetes insipidus (DI) on water deprivation test.

Though the results could not be confirmed with genetic testing due to infrastructural constraints at our set-up, the afore said constellation of symptoms led us to the clinical diagnosis of WS (Table 1). ${ }^{3}$ )

His blood sugar was $315 \mathrm{mg} / \mathrm{dl}$ and dose of insulin was titrated accordingly. Serum sodium level was $127 \mathrm{mmol} / \mathrm{L}$, with mildly increased serum urea and creatinine. Neurological examination revealed gait abnormality with ataxia. No cerebellar signs were noted; thereby indicating a possible abnormality in propriocetpive vestibular function. On psychometric assessment, Weschlar test scored intelligence quotient at 76 . There was one suicidal attempt 2 years back-Beck Suicidal Intent score was 25 (moderate).

To manage the manic symptom, aripirazole $10 \mathrm{mg}$ in two divided doses was prescribed and increased to $10 \mathrm{mg}$ twice daily after 7 days. Within 15 days, his mood normalized. At 3 months follow up, though his other symptoms were deteriorating; he was doing well from the psychiatric point of view.

\section{DISCUSSION}

WS is a rare (estimated prevalence 1 in 770,000) ${ }^{3)}$ auto- somal recessive neuroendocrinal degenerative disorder caused by mutation in WFS1 gene which encodes for a endoplasmic reticulam (ER) transmembrane protein wolframin. ${ }^{1,3)}$ Since the discovery of a specific causative mutation in WFS1 or wolframin gene, significant progress has been made both with the disease itself and also with several other associated manifestations of its aberration, among which psychiatric disorder feature prominently.

It is estimated that as many as $1 \%$ of the general population could carry mutations in the WFS1 gene ${ }^{3)}$ and the heterozygosity for the WFS1 mutations has been reported to be a significant risk factor for psychiatric illnesses. ${ }^{5,6}$ Several psychiatric signs and symptoms are reported in homozygous or compound heterozygous patients with wolframin gene. A high probability of carrying a single wolframin mutation and a statistically significant excess of psychiatric hospitalizations, suicidal behavior, completed suicides, and self-reports of mental illness, over spouse controls ${ }^{6}$ has been found in first degree relatives of patients with WS. An isolated mutation in the WFS1 gene have been reported in patients with bipolar disorder (BD), major depression, schizophrenia, and suicide victims even in absence of sine qua non features of WS. ${ }^{7)}$ There are conflicting reports regarding connection between WFS1 gene and BD. Though no association of WFS1 polymorphisms and expression level in postmortem tissue of Japanese BD 
patients was found, ${ }^{8)}$ a recent meta-analysis of genomewide expression studies on BD revealed WFS1 expression in prefrontal cortex to be significantly correlated with BD. ${ }^{9)}$ A report showing DI with mania ${ }^{10)}$ and locating one locus on linkage analysis to chromosome 4 also empower the above findings. ${ }^{11)}$

Impaired ER stress is proposed to be associated with BD. XBP1 protein is a transcription factor of ER stress pathway. In animal model WFS1 gene is found to be induced in response to ER stress via XBP1 that negatively regulates ER stress, normally. ${ }^{12)}$ This may have a profound implication regarding genetic causation of $\mathrm{BD}$ itself.

As valproate carries a risk of weight gain and insulin resistance, and can also induce ER stress; ${ }^{13)}$ it is best avoided in patients of WS. Lithium is better than valproate in terms of potential ER stress induction; ${ }^{14)}$ however, it can aggravate preexisting renal dysfunction in this group. Among the antipsychotics, keeping the metabolic, cardiac and other side effect profiles and local availability in mind, aripiprazole was selected. In our case DM was the earliest to manifest, followed by visual, auditory and gait abnormalities in that order. This is in accordance with the classically reported cases. Interestingly, our patient also showed a decreased serum sodium level on further investigations, despite water deprivation. While this might be indicative of DI; it can also be attributed to concurrent presence of DM and resultant osmotic water accumulation.

Based on this report, we suggest use of aripiprazole in patients of WS presenting with mania. The drug is metabolically safe, as well as effective in managing the psychiatric symptoms. We acknowledge that availability of WFS1 mutation report could have made the case much stronger, but clinical symptom constellation is too discreet to hint at any other diagnosis.

\section{REFERENCES}

1. Barrett TG, Bundey SE, Macleod AF. Neurodegeneration and diabetes: UK nationwide study of Wolfram (DIDMOAD) syndrome. Lancet 1995;346:1458-1463.

2. Swift RG, Polymeropoulos MH, Torres R, Swift M. Predisposition of Wolfram syndrome heterozygotes to psychiatric illness. Mol Psychiatry 1998;3:86-91.

3. Farmer A, Aymé S, de Heredia ML, Maffei P, McCafferty $\mathrm{S}$, Młynarski W, et al. EURO-WABB: an EU rare diseases registry for Wolfram syndrome, Alström syndrome and Bardet-Biedl syndrome. BMC Pediatr 2013;13:130.

4. Hershey T, Lugar HM, Shimony JS, Rutlin J, Koller JM, Perantie DC, et al; Washington University Wolfram Study Group. Early brain vulnerability in Wolfram syndrome. PLoS One 2012;7:e40604.

5. Swift RG, Perkins DO, Chase CL, Sadler DB, Swift M. Psychiatric disorders in 36 families with Wolfram syndrome. Am J Psychiatry 1991;148:775-779.

6. Swift M, Swift RG. Wolframin mutations and hospitalization for psychiatric illness. Mol Psychiatry 2005;10:799-803.

7. Strom TM, Hörtnagel K, Hofmann S, Gekeler F, Scharfe C, Rabl W, et al. Diabetes insipidus, diabetes mellitus, optic atrophy and deafness (DIDMOAD) caused by mutations in a novel gene (wolframin) coding for a predicted transmembrane protein. Hum Mol Genet 1998;7:2021-2028.

8. Kato $\mathrm{T}$, Iwamoto $\mathrm{K}$, Washizuka S, Mori $\mathrm{K}$, Tajima $\mathrm{O}$, Akiyama $\mathrm{T}$, et al. No association of mutations and $m R N A$ expression of WFS1/wolframin with bipolar disorder in humans. Neurosci Lett 2003;338:21-24.

9. Seifuddin F, Pirooznia M, Judy JT, Goes FS, Potash JB, Zandi PP. Systematic review of genome-wide gene expression studies of bipolar disorder. BMC Psychiatry 2013;13:213.

10. Sachdeva JK, Chalana H. Central Diabetes Insipidus presenting with manic symptoms. Asian J Psychiatr 2011;4: 226-227.

11. Blackwood DHR, He L, Morris SW, McLean A, Whitton $\mathrm{C}$, Thomson $\mathrm{M}$, et al. A locus for bipolar affective disorder on chromosome 4p. Nature Genet 1996;12;427-430.

12. Fonseca SG, Ishigaki S, Oslowski CM, Lu S, Lipson KL, Ghosh $\mathrm{R}$, et al. Wolfram syndrome 1 gene negatively regulates ER stress signaling in rodent and human cells. $J$ Clin Invest 2010;120:744-755.

13. Chuang DM. The antiapoptotic actions of mood stabilizers: molecular mechanisms and therapeutic potentials. Ann NY Acad Sci 2005;1053:195-204.

14. Punapart M, Eltermaa M, Oflijan J, Sütt S, Must A, Kõks $\mathrm{S}$, et al. Effect of chronic valproic Acid treatment on hepatic gene expression profile in wfs1 knockout mouse. PPAR Res 2014;2014:349525. 